CuPAUAM. 17-1990, 277-306

\title{
INSCRIPCIONES DEL NORTE Y SUDOESTE DE LA PROVINCIA DE CACERES: REVISION Y NUEVAS APORTACIONES
}

\author{
J.L. Gamallo BarRanco \\ H. GIMENO PASCUAL \\ Equipo de REDACCION de Hispania Epigraphica \\ Departamento Historia ANTIGUa \\ UNIVERSIDAD CUMPLUTENSE MADRID
}

\section{Resumen}

Se publican o revisan diversos epígrafes romanos de la provincia de Cáceres.

\section{Summary}

This paper edits or revises some Roman inscriptions from Cáceres.

La provincia de Cáceres, abundante en hallazgos epigráficos, continúa proporcionando nuevos ejemplos al margen de los ya editados, que en muchos casos, desde época de Hübner o Roso de Luna, han sido dados por perdidos y, revisados, pueden ofrecer nuevos datos que enriquezcan los conocimientos sobre la epigrafía de la región. Salvo las estelas que se presentan de la zona Norte, el resto pertenece al área trujillana y se inscriben en el ambiente epigráfico usual del sudoeste de la provincia.

Queremos dejar constancia, de nuestro agradecimiento, especialmente, a Valentín Soria Sánchez, por su amabilidad al comunicarnos el hallazgo y paradero de las inscripciones número 9 , $10,11,12$ y 13, al acompañarnos en la observación directa de las mismas y asímismo por algunas sugerencias por él propuestas. De igual forma a Josep Vilella por la ayuda proporcionada en la búsqueda y fotografiado de las inscripciones.

\section{ABERTURA}

1. Bloque de granito roto en la parte izquierda y por abajo, debido a su reutilización como jamba izquierda en la ventana de una casa semiderruída, propiedad de $\mathrm{D}^{\mathrm{a}}$ Aurelia Mena en la calle del Resbaladero. En la esquina del lado derecho del bloque se ha practicado un corte verti- 
cal para formar una arista. El campo epigráfico está rebajado. Medidas: $(47)$ x $(35,5)$ x 18,5. Letras: 1.1: 5; 1. 2-3: 6,5. Interpunción: punto y triángulo (Fig. 1).

Elea Ta-

ncini $\cdot f($ ilia).

$[h(i c)] \cdot s($ ita $) \cdot e(s t) \cdot s(i t) \cdot t($ ibi $) \cdot t($ erra $) \cdot l($ evis $)$

Letra capital cuadrada profundamente grabada.

La onomástica de la difunta es indígena El nombre del padre, Tancinus, es muy abundante en Lusitania. Elea, antropónimo no atestiguado en la Península, pertenece sin embargo, al grupo ya conocido de nombres indígenas con radical ${ }^{*} e$, (Albertos, 1966, p. 112 ss.). Por el formulario se fecharía en el siglo I.

2. Estela de granito rota en la parte inferior y en la esquina inferior izquierda. La cabecera es semicircular y en sus extremos inferiores dos aristas permiten que ésta destaque del cuerpo de la estela. En la parte superior del frente, ocupando la cabecera sermicircular y parte del cuerpo de la estela hay una rosa hexapétala con umbo en relieve inscrita en un doble circulo. En la parte inferior del motivo decorativo existen dos pequeños triángulos afrontados. Está pulida en todas sus caras, menos en la posterior. Fue hallada en labores agrícolas en una finca cerca del límite de Abertura con Villamesías. Actualmente se conserva en una finca propiedad de $\mathrm{D}^{a}$ Aurelia Mena en las proximidades del pueblo. Medidas: $(68) \times 40 \times 7$. Letras:I. 1: 5; 1. 2: 4,5; 1. 3: 5. Interpunción: punto. (Fig. 2).

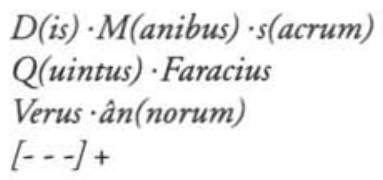

Capital cuadrada algo alargada, R abierta, A sin travesaño. En 1.4 la + es un trazo vertical, I o L. El difunto tiene tria nomina, aunque no indica la filiaci6n. Lleva un cognomen latino de los más comunes; el nomen, desconocido en la Península, se atestigua en CIL VI 384 I 16 y CIL X 5232 (Krahe, 1929, p. 50). Se fecharía a partir de fines del siglo I.

3. Estela de granito con cabecera semicircular, en cuyo centro hay un creciente lunar. Ligeramente rota en el lado derecho, de forma que afecta a la última letra de cada línea. Pulida en todas sus caras excepto en la posterior. Fue hallada como la anterior y se conserva en el mismo sitio. Medidas: $68 \times 35 \times 19$. Letras: 6 . Interpunción: triángulo. (Fig. 3).

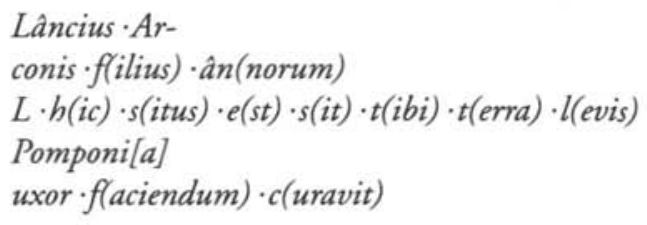


Capital cuadrada profundamente grabada y de buena factura con pies señalados, $\mathrm{P}$ abierta, $\mathrm{E}$ y F con los trazos horizontales inclinados hacia arriba.

La onomástica y el sistema de filiación del difunto, típicamente indígenas y bien documentados en la zona (Domínguez de la Concha, 1990: Lancius, nn. 1204-1210; Arco: nn. 325-350), contrasta con el antropónimo latino de la esposa, que utiliza un nomen como cognomen, fenómeno que se produce con relativa frecuencia en áreas de Hispania de pervivencia indígena. Se fecharía en el siglo I.

4. Estela de granito que sirve de banco en un patio de la casa de $\mathrm{D}^{\mathrm{a}}$ Luciana Rubio Tardío, adosada al suelo por su lado derecho en posición horizontal. Medidas: 81 x (29) x 15,5. Letras: 5. Interpunción: punto; a partir de la l. 5 es silábica. (Fig. 4).

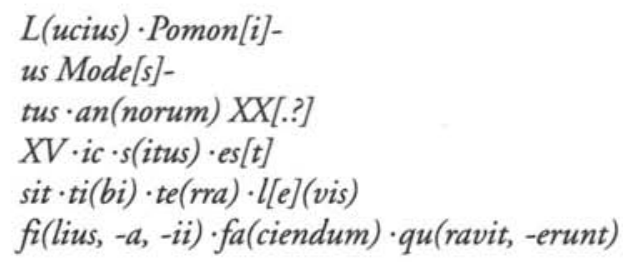

Capital cuadrada algo redondeada con los remates señalados. CPILC nn. 3 (Fernández Oxea, 1951, p. 190) y 6 (Roso de Luna 1904, p. 129; ILER 3611). L 1, EPOAMONI, CPILC nº 6; 1. 6, EI.FA.QV., CPILC n 6. En 1.4 se omite la $\mathrm{H}$ de ic. En $1.6 \mathrm{Q}$ por C. CPILC considera que son dos piezas distintas aunque similares. Respecto al nombre Pomon[i]us, no atestiguado de momento, teniendo en cuenta los restantes errores que existen en el texto, se podría pensar en Pom $<p>$ on [i] $u$. Se fecharía en el siglo I.

5. Fragmento correspondiente a la parte superior derecha de una estela de granito. Fue cortada horizontalmente en las partes superior y derecha y está rota en el lado izquierdo. En la parte superior tiene una rosa hexapétala en relieve con umbo rehundido, inscrita en un círculo. En la parte derecha conserva restos de otra moldura circular. En el extremo inferior derecho del círculo se conserva una escuadra. Se encontró y se guarda como las $n^{\circ} 2$ y 3 . Medidas: (50) x (8) x 20. Letras: 6; Interpunción: punto. (Fig. 5).

$D$ (is) $M$ (anibus) s(acrum)

[.] oscia

Capital cuadrada con los remates ligeros, de buena factura. La $S$ de 1.1 está muy desgastada

En 1.2 el nombre de la difunta podría ser [R]oscia y detrás estaría el cognomen. Se fecha a fines del siglo I-II.

6. Parte inferior, a su vez partida en dos, de una estela de granito con las caras anterior y laterales pulidas. La parte posterior presenta un surco transversal y una especie de recuadro debido probablemente a la reja de un arado. Se conserva como la $n^{\circ} 4$. Medidas: $(38+57=95)$ x 34 x 16,5. Letras: 6; 1. 3: 5. Interpunción: punto. (Fig. 6). 
$+++[$ an $($ norum $)]$

$X V I \quad h(i c) \cdot s(i t u s,-a) \cdot e(s t) \cdot s(i t) \cdot t(i b i) \cdot t($ erra $)$

$l($ evis $) \cdot$ Âfelia $\cdot$ avia

$d(e) \cdot s(u o) \cdot f(e c i t)$

Capital cuadrada rústica e irregular. El aparente nexo entre la I y la A del antropónimo de $\mathrm{l}$. 3 es una rotura existente en la piedra.

Afelia (1) es un antropónimo griego que presenta aquí la grafía $\mathrm{F}$ por $\mathrm{PH}$ e I por E. No documentado aún en la Península, sí, aunque raramente, aparece en otras partes del Imperio (Solin, 1982, vol. II, p. 857, s.v. Aphelea).

\section{ALCOLLARIN}

7. Estela de granito rota en la parte derecha, hacia la mitad, cubierta de cal, empotrada en la fachada de una casa de la calle Abertura. Medidas: 58 x39 x ?. Letras: 6; Interpunción: punto (Fig. 8).

\section{Celtiatus}

Veniati (filius)

$h(i c) \cdot s($ itus $) \cdot e(s t) \cdot s(i t) \cdot t(i b i) \cdot t($ erra $) \cdot[l($ evis $)]$

Roso de Luna, 1904, p. 554 (CPILC n 30).

Letra capital cuadrada, con los trazos de la $\mathrm{V}, \mathrm{N}$ y A redondeados.

La onomástica es indígena: Celtiatus pertenece al grupo de derivados de Celtius, antropónimo bien documentado en Lusitania (Domínguez de la Concha 1990, $\mathrm{n}^{\circ}$ 885-901); el genitivo Veniati, pertenece al grupo de radical *ven (cf. Albertos 1966, p. 246-247) al que pertenecen otros ejemplos de Lusitania (Palomar 1957, pp. 101 y 109). Se fecharía en el siglo I.

\section{CONQUISTA DE LA SIERRA}

8. Ara de granito con foculus. Presenta un frente liso, mientras que en la parte posterior arriba tiene dos molduras rectas escalonadas que dan paso al fuste, lo mismo que abajo, donde dan paso a la base. Se conserva a la entrada de una casa en la calle General Valera $n^{\circ} 6$, donde sirve de banco apoyada sobre dos bloques de granito y adosada a la pared. El campo epigráfico está sumamente erosionado y ocupa sólo aproximadamente un tercio de la superficie total. Medidas: 80 × 37 × 25. Letras 1.1:6; 1. 2: 5,5; 1. 3: 6,5. (Figs. 7 y 9).

Flo + a

$\mathrm{Pla}+++$

a(nimo) l(ibens) v(otum) s(olvit)

(1) Es posible que haya que identificar esta inscripción con Roso de Luna 1904, p. 120, no 27 (Mélida, 1924, p.117, $\mathrm{n}^{\circ}$ 319) y CPILC n8, aunque los tres sólo dan las 1.3 y 4 : L. A. EL'AA/ DS, Roso de Luna: L. A. E. L. // A / D.S., CPILC. 
En 1.1 la + representan restos de dos trazos venicales, el segundo más alto, tal vez nexo NI, resultaría un nomen Flonia inédito en la Península, pero atestiguado en CIL V 2253 (Krahe, 1929, p. 51). En 1.2 la primera + corresponde a un trazo vertical que se curva hacia la derecha en la parte superior, quizá C o R. La segunda + corresponde a un trazo vertical que puede ser To I, aunque el travesaño de la $\mathrm{T}$ no es muy seguro. La tercera + puede ser una $\mathrm{A}$, ya que parecen existir restos del segundo trazo oblicuo de dicha letra

Debido al mal estado de conservación de la piedra no es posible saber si en 1.2 estaría el nombre de la divinidad o el cognomen de Flonia, aunque preferimos esta segunda posibilidad,ya que Flonia es nomen.

\section{GARCIAZ}

9. Ara de granito con coronamiento y base moldurados. En la parte superior del coronamiento presenta un orificio cuadrangular que pudo ser el foculus y luego se le practicó un rebaje en el lado derecho y una hendidura para su reutilización y justo en este mismo lado, entre las dos molduras, tiene incrustada aún una anilla de hierro. En el frente, la segunda moldura del coronamiento falta en su mitad izquierda afectando a la 1.2 y en la base las molduras están completamente repicadas. Las cuatro caras están pulidas. Servía en la iglesia parroquial para sujetar el cepillo. Se conserva provisionalmente en el garaje de una casa junto a la iglesia, mientras duren las obras de restauración de ésta. Medidas: 62,5 x 35 x 30. Letras: 1. 1: 5; 1. 2: 4; 1. 3-4: 5,5. Interpunción: triángulo. (Fig. 10)

Marti s(acrum)

[-] [-- - ] ]

Rusticus

a(nimo) $\cdot l($ ibens $) \cdot v($ otum $) \cdot s($ olvit $)$

Soria Sánchez, 1980, p. 29; id. 1983, p. 208.

Letra capital cuadrada con remates muy marcados en 1.3 - 4. Las letras de 1.1-2 están erosionadas y han debido sufrir golpes. La I de 1.1 se puede confundir con una V debido a que hay un trazo inclinado hacia la derecha, tal vez hecho intencionadamente en un momento posterior (2). La A de 1.4 con travesaño en forma de ángulo, la de 1.1 aunque parece recto, tiene un desconchón que presenta la forma angular. La forma de las letras de las dos últimas líneas con pies y ápices muy marcados y abiertos, y el travesaño de las A sugieren una fecha algo tardía, a partir del siglo III. La I de la ligadura TI de 1.3 sobrepasa bastante la caja del renglón, y la segunda V es minuta y está casi inclusa en la $\mathrm{C}$.

En 1.2 estaría [- Cla.?]udius. Se trata de un individuo ingenuus que hace una dedicación a Marte, culto bien arraigado en las zonas lusitana y vettona.

(2) Agradecemos a A. M. Canto la lectura e interpretación de l. 1. 


\section{JARANDILLA DE LA VERA}

10. Estela de granito casi cilíndrica, rota en las partes superior e inferior, lo que afecta a la última línea conservada del texto. Se halló en 1990 en un campo a dos kilómetros de Jarandilla. Se conserva en la "ramá" o secadero de una finca en las proximidades del pueblo. Medidas: (54) x 26 x 19. Letras: 7-5,5; (Figs. 11 y 12).

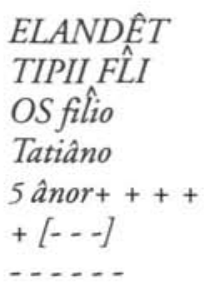

Capital cuadrada muy irregular, basta y rústica, profundamente grabada.

Dada la irregularidad y rusticidad de las letras, la interpretación resulta problemática. En l. 1, al final nexo ET. En 1.2 las cinco primeras letras son bastante claras, TIPII, a la F sigue una especie de U que por comparación con la de la 1.3 puede ser una ligadura LI. En 1.3, después de OS FI, hay una U, ligadura LI. En 1.4, nexo AN. En 1.5 primero hay un nexo AN, luego O, y seguramente $\mathrm{R}$, las cruces indicarian la edad II, representada por los inicios de dos rasgos verticales; $\mathrm{y}$ el comienzo de la fórmula funeraria $i(c)$ ?, probablemente $\sin \mathrm{H}$ ya que le sigue el trazo curvo superior de una $S$, sin duda s(itus), continuada en la + de 1.6, que representa el travesaño superior horizontal de una $\mathrm{E}$.

En 1.1-2 se puede distinguir un antropónimo Elandet(us?). Aunque no abundante, el radical ${ }^{*} e l$ no es raro en la zona (Palomar, 1957, p. 72; Dominguez de la Concha 1990, nn. 1139-1147, destaca que los derivados de Elan- se centran en la zona astur celtibérica, excepción hecha de los casos citados, aparecidos en Yecla de Yeltes, Traguntia y Cáceres), En 1.2, aparece un genitivo Tipii que sería la filiación, antropónimo cuyo radical carece de paralelos en Hispania. Sería más fácil leer P por R, ya que al menos la forma Tir- si es conocida (Albertos 1966, p. 227).

A continuación se lee FLI/OS, que tampoco tiene sentido: como un acusativo plural es inviable, lo mejor sería considerar OS por VS, y así concordaría con el nominativo de l.1. Por tanto cabría interpretar que el lapicida hubiera olvidado la I detrás de F, o bien si tenemos en cuenta el mayor tamaño de ésta ver un nexo FI, con lo cual se especificaría la filiación por entero.

En cuanto al nombre del hijo, Tatiânus, tampoco encontramos paralelos, aunque si existen nombres como Tata, Tato, Tatta, Tattaia, etc. (Krahe, 1929, p. 111).

La interpretación hipotética que proponemos sería:

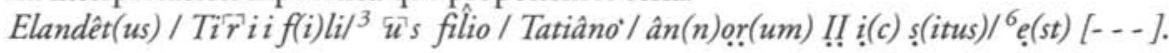

\section{PUERTO DE SANTA CRUZ}

11. Estela de granito partida en dos, reutilizada en las jambas derecha e izquierda de una puerta en la antigua calle de la Cilla, hoy del Doctor Izarra. La fractura longitudinal afecta a la letra central de todas las líneas. Según testimonio de un vecino, antes estuvo entera en la fachada 
de la Casa de los Diezmos y Primicias. Medidas: frag. izdo. 58 x (19) x 20; frag. dcho. 58 x (19) x 20. Letras: 6; 1.6: 5 . Interpunción: triángulo (Figs. 13 y 14).

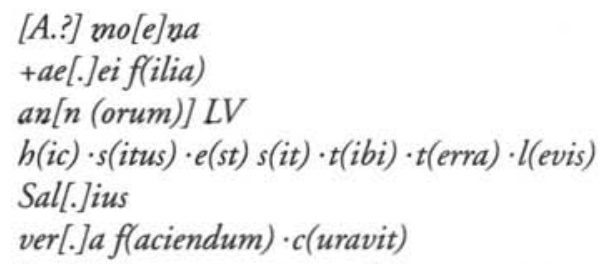

En 1.2 la + representa el trazo curvo superior sin cerrar de una letra, seguramente C, ¿Ca[l]ei?. En 1.6 quizá ver[n]a. Mientras que la difunta lleva ya un nombre romano, la filiación sigue siendo de tipo indígena, lo mismo que el nombre del padre.

Por el formulario y la ausencia de D.M., se fecha en el siglo I.

\section{TORREJON EL RUBIO}

12. Estela de granito rojizo con el busto del difunto en el interior de una hornacina semicircular en la parte superior del frente. En la parte alta de la estela presenta un rebaje con un orificio circular en el centro. Se halló en el lugar de Los Toriles en la finca San Rafael, donde parece existir una necrópolis. Se conserva en una propiedad particular hincada a una profundidad de unos $50 \mathrm{~cm}$. Medidas: 135 +aprox. 50 x 40 x 30. Letras: 7 . Interpunción: punto. (Fig. 15 y 16).

Calaetus
Coropoti
$f($ ilius $) \cdot b($ ic $) \cdot s($ itus $) \cdot e(s t)$

Soria Sánchez, 1985, p. 489 (HEp 1,1989,186).

Capital cuadrada algo alargada, de trazo profundo. La onomástica es típicamente indígena. Aunque el nombre del padre es la primera vez que aparece en la península, antropónimos derivados de Coro- están bien atestiguados (Albertos 1966, pp. 95-97; Dominguez de la Concha 1990, nn. 1012-1023). Se fecha en el siglo I, algo temprano, por el tipo de formulario.

\section{VILLAMESIAS}

13. Estela de granito con cabecera semicircular. Medidas: 130 x 47 x ?. Letras: 109 . Interpunción: punto. Lineas guía muy marcadas. Está empotrada en el suelo del atrio de la iglesia parroquial, de donde se sacó hace tres o cuatro años cuando reforrnaron la plaza. (Fig,. 17)

C(aia.?) Iulia

Bovâna

Triti $\cdot f($ ilia $)$

hic $\cdot$ s(ita)

est 
Letra capital cuadrada. R abierta. En 1.1 se ve la parte superior de una C. CIL II 666; Roso de Luna, 1905, p. 64, n 65 (CPILC na 636); HAE 759. La difunta porta un nomen latino y un cognomen indígena, este último aparece en Abertura y en Coria (Domínguez de la Concha 1990, nn. 495-496). El hecho de que aparezca un praenomen para una mujer denota cierto arcaísmo. Tanto el nombre del padre como el tipo de filiación son indígenas. Por el formulario, el tipo de letra y la utilización de $C$ (aia) se fecha en el siglo I temprano.

14. Estela de granito con cabecera semicircular con roseta octapétala inscrita en un círculo doble, y debajo sendas hederae enmarcándolo. Está rota en la parte superior y mitad inferior derecha. Está empotrada formando el dintel de una ventana, en la fachada de una casa de la calle Nueva donde coincide con la calle Martín Bravo. Medidas: 116 x 35 x 8. Letras: 1.1, 6; 1.2-3-4, 5; 1.5,6>5; 1.7,5>4,5; 1.8,5; 1.9,7(F), 10(C); O,3,5. Interpunción: triángulo y punto. (Fig. 18).

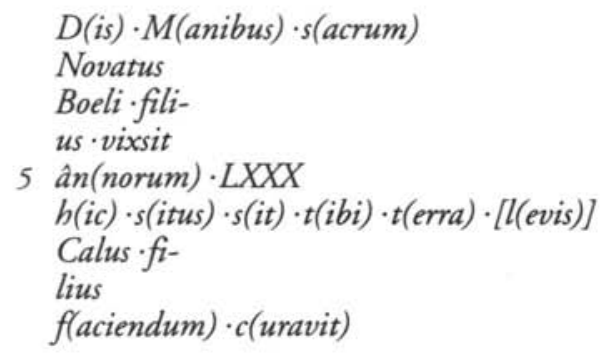

Capital cuadrada con tendencia a la actuaria El segundo trazo de la $\mathrm{N}$ de 1.1 se prolonga hacia arriba y la derecha A sin travesaño. En $1.7 \mathrm{C}$ y A se tocan en los extremos inferiores. En 1.4 ultracorrección XS. El difunto con cognomen latino tiene un padre y un hijo con nombres indígenas no atestiguados hasta el momento en la Península, aunque el del dedicante puede incluirse en los nombres del grupo $\mathrm{Cal}$ - bien conocido en la zona. Por el formulario se fecha a fines del siglo I-II.

15. Estela de granito algo desgastada por el lado derecho. Presenta la cabecera redondeada y sendas molduras en los laterales de la misma. El campo epigráfico está enmarcado por una moldura. Medidas: 205 x 44 x 24; campo epigráfico empieza a $27 \mathrm{~cm}$. de la parte superior y ocupa la cuarta parte. Letras: 6 . Interpunción: triángulo. Se conserva, sirviendo de banco adosada a la pared por el lado izquierdo, en el corral de una casa de Da Antonia Saturnina Rubio, Travesía Moscardó n5. (Fig. 19).

\author{
Valeria . \\ $Q$ (uinti) $f$ (ilia) Mod - \\ esta $\cdot h($ ic $) \cdot s($ ita $) \cdot e(s t)$ \\ $s($ it) $\cdot t($ ibi) $\cdot t($ erra $) \cdot l($ evis $)$ \\ 5 anno(rum) $L$
}

Letra capital cuadrada de buena factura. $\mathrm{O}$ y $\mathrm{Q}$ muy redondas.

CIL II 669; Roso de Luna, 1905, p. 63, n60 (CPILC n 628); HAE740. L 4, om. CIL; 1.5, ANNOR L; Roso de Luna. 
Tanto el nombre como la filiación de la difunta son latinos. Se trata de una ingenua. Se fecha en el siglo $\mathrm{I}$.

16. Fragmento inferior izquierdo de una estela de granito, con el campo epigráfico enmarcado por una moldura. Frente y cara lateral pulidas. Medidas: (38) x (29) x 18. Letras: 6. Interpunción: punto. Se halla en el porche de una casa de la carretera nacional V Madrid-Badajoz, a la entrada del pueblo. (Lám. XI, fig. 21).

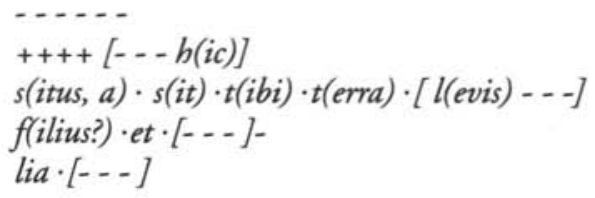

En la parte que falta aparecería el nombre del difunto y el principio de la fórmula funeraria. Al final de 1.2 estaría el nombre de uno de los dedicantes y al final de 1.3 , seguramente, la primera parte del segundo dedicante, una mujer, y detrás la relación familiar de esta última con el difunto y tal vez la formula final de dedicación. 


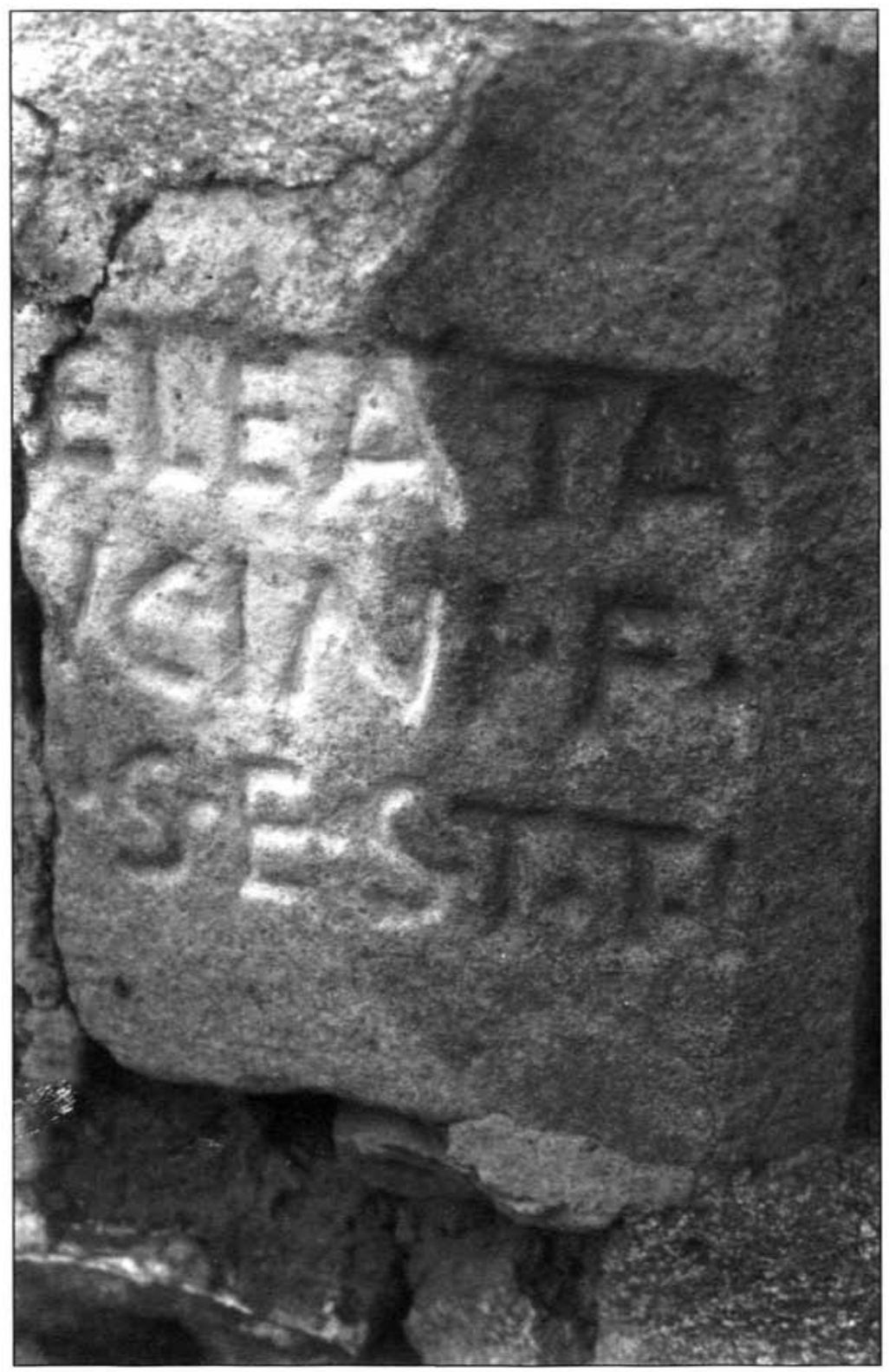

Figura 1: Abertura 


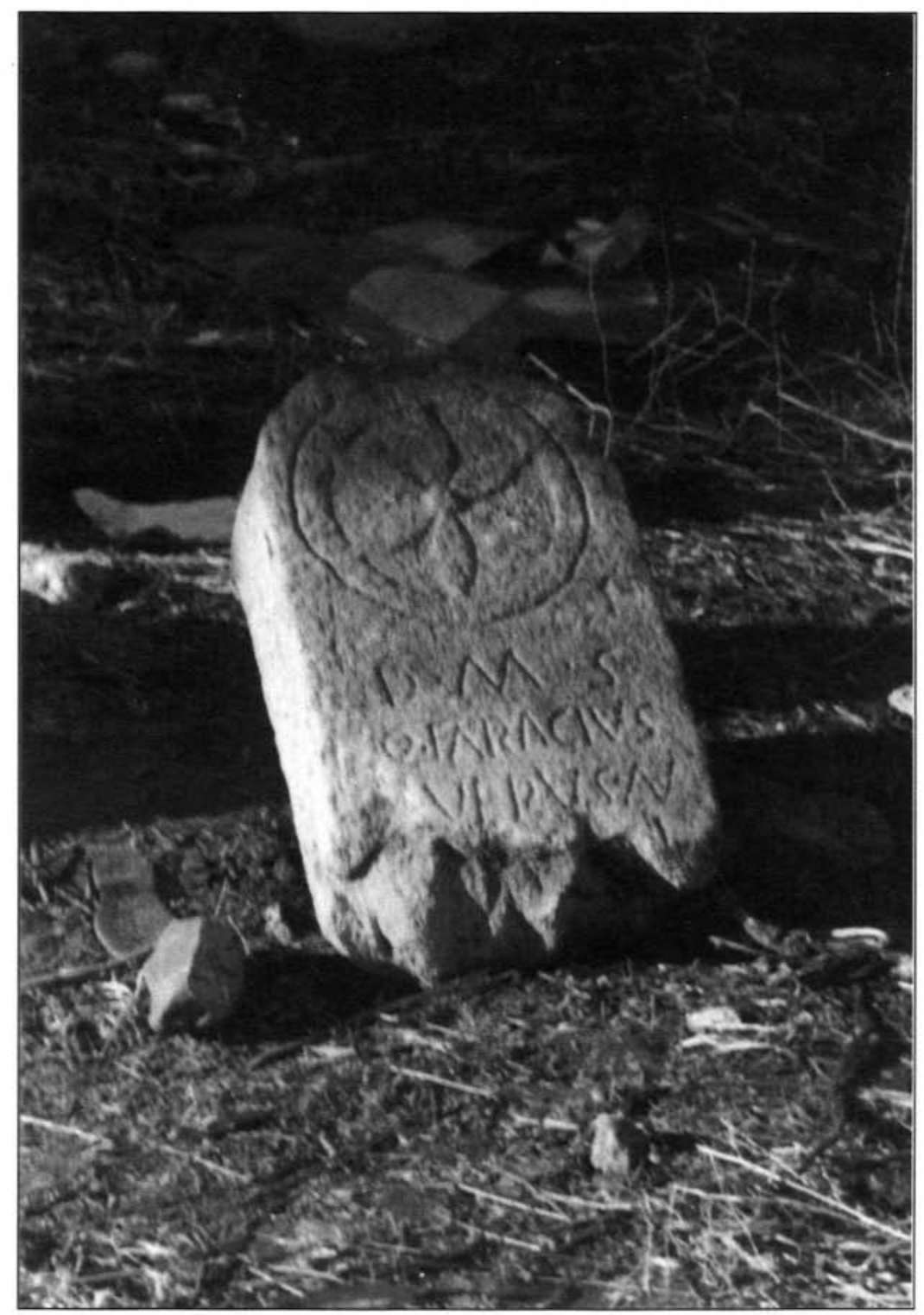

Figura 2: Abertura 


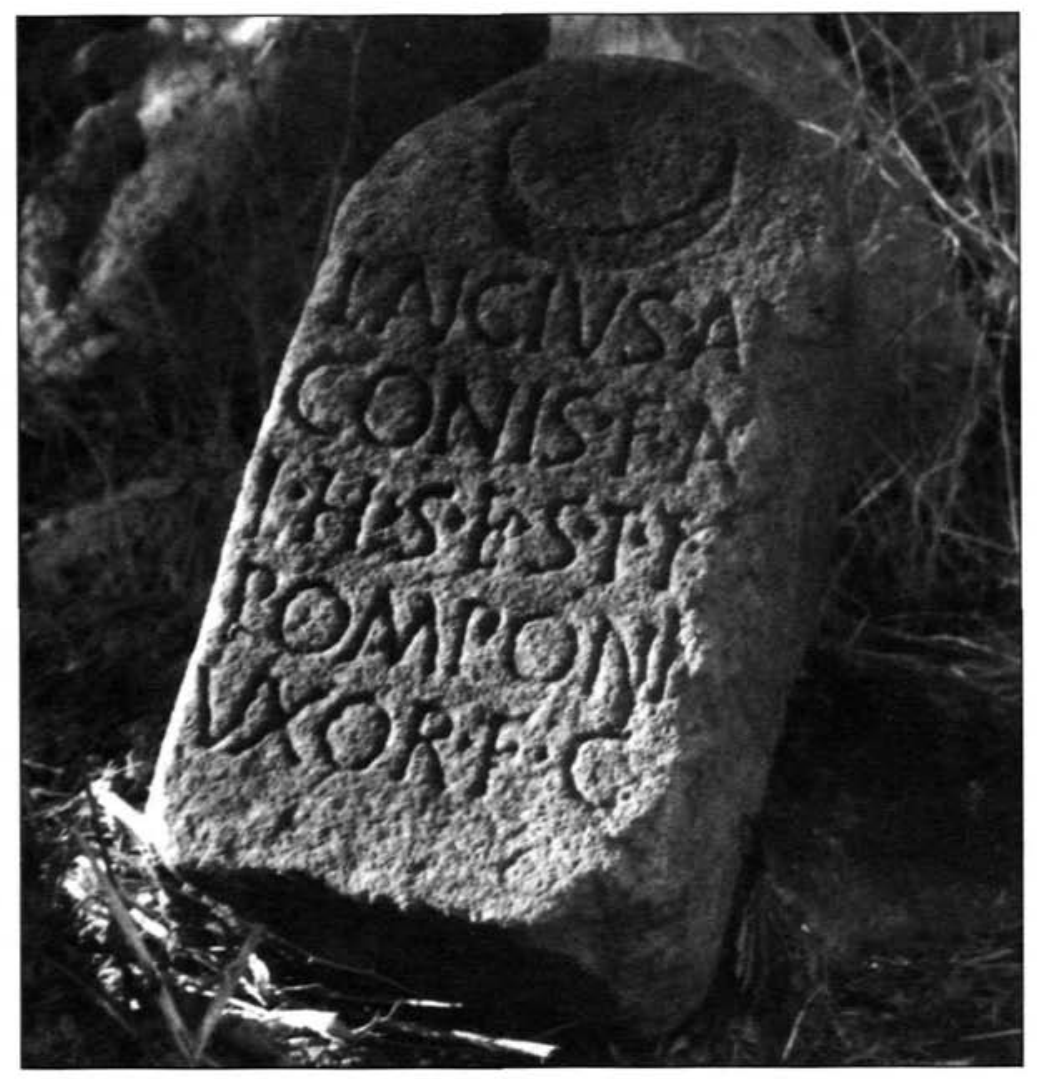

Figura 3: Abertura 


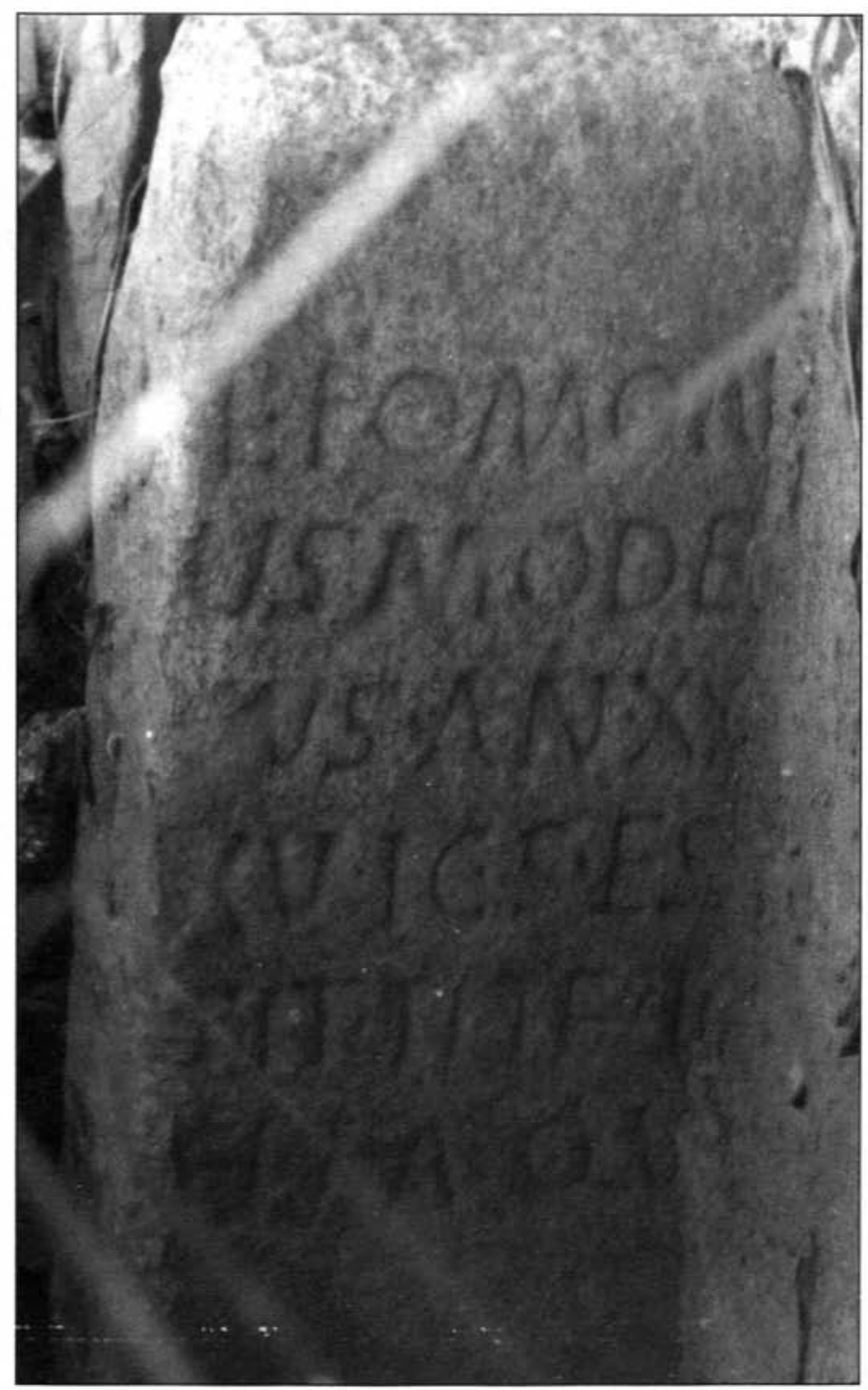

Figura 4: Abertura 


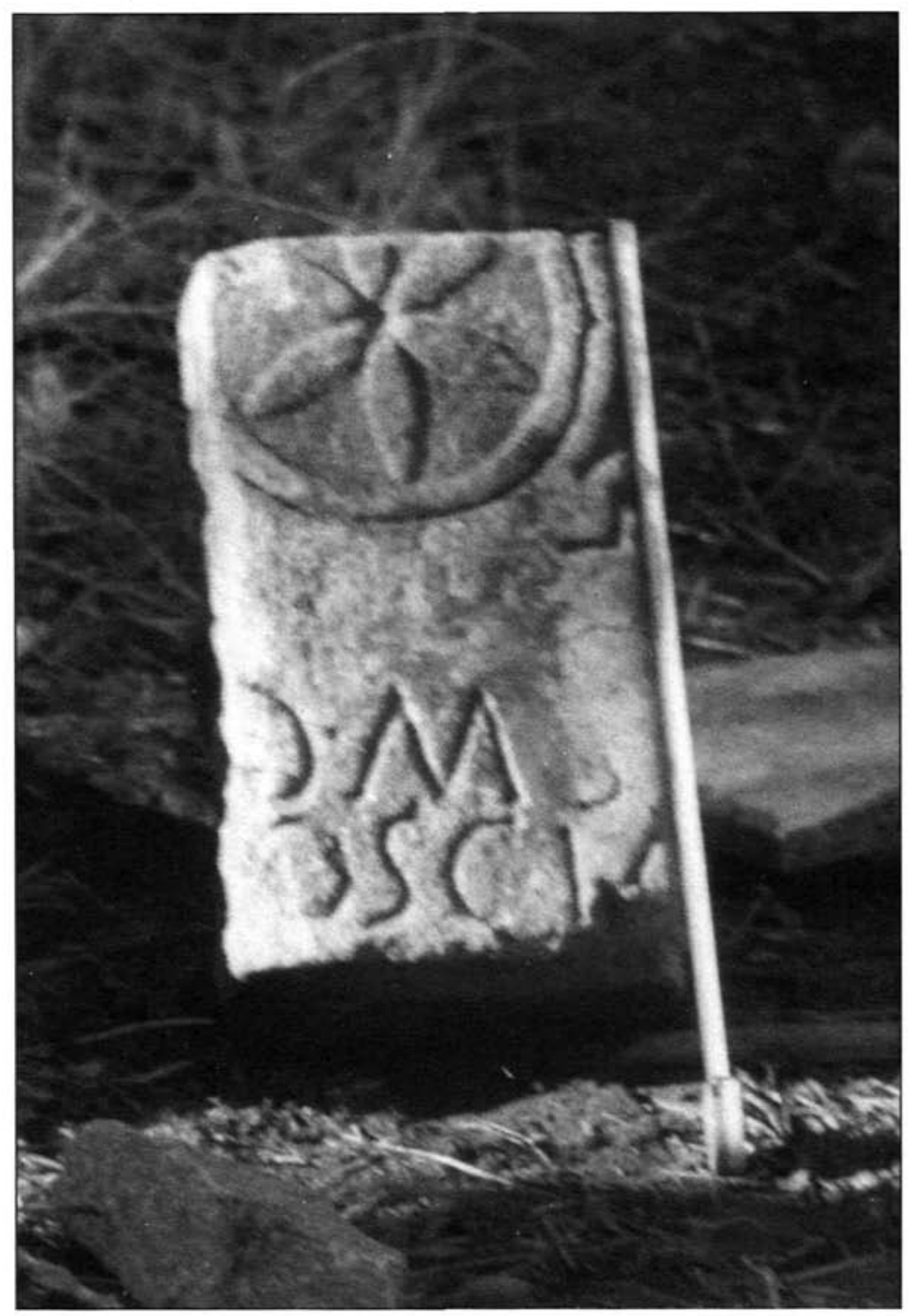

Figura 5: Abertura 


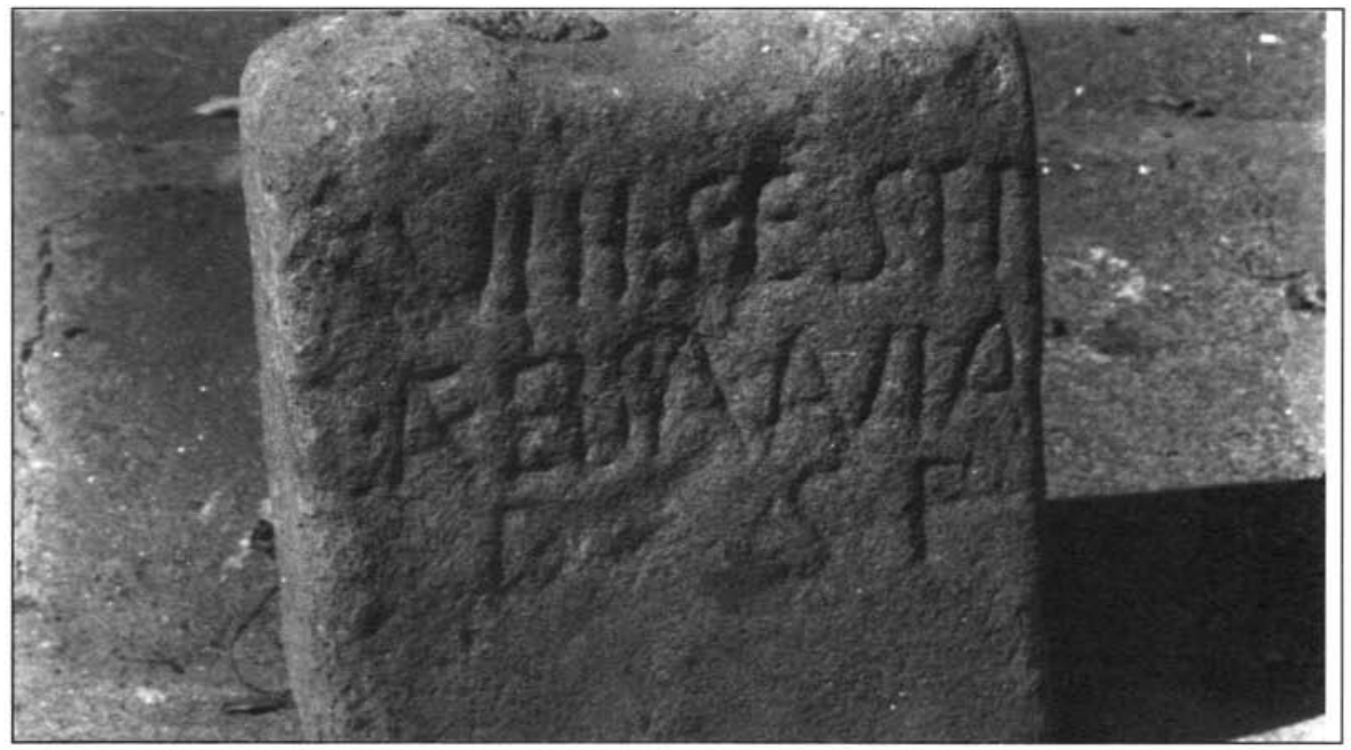

Figura 6: Abertura

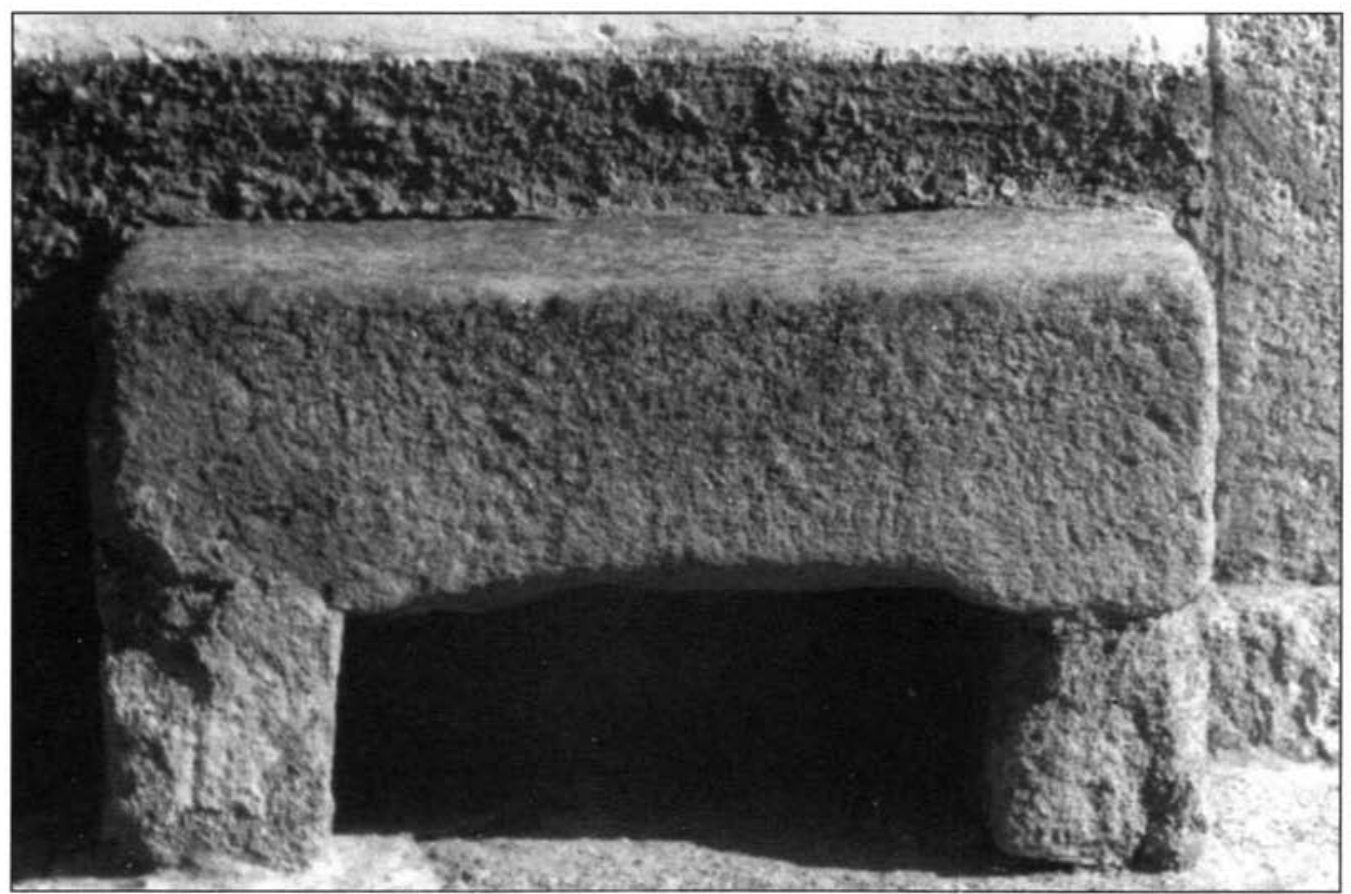

Figura 7: Conquista de la Sierra 


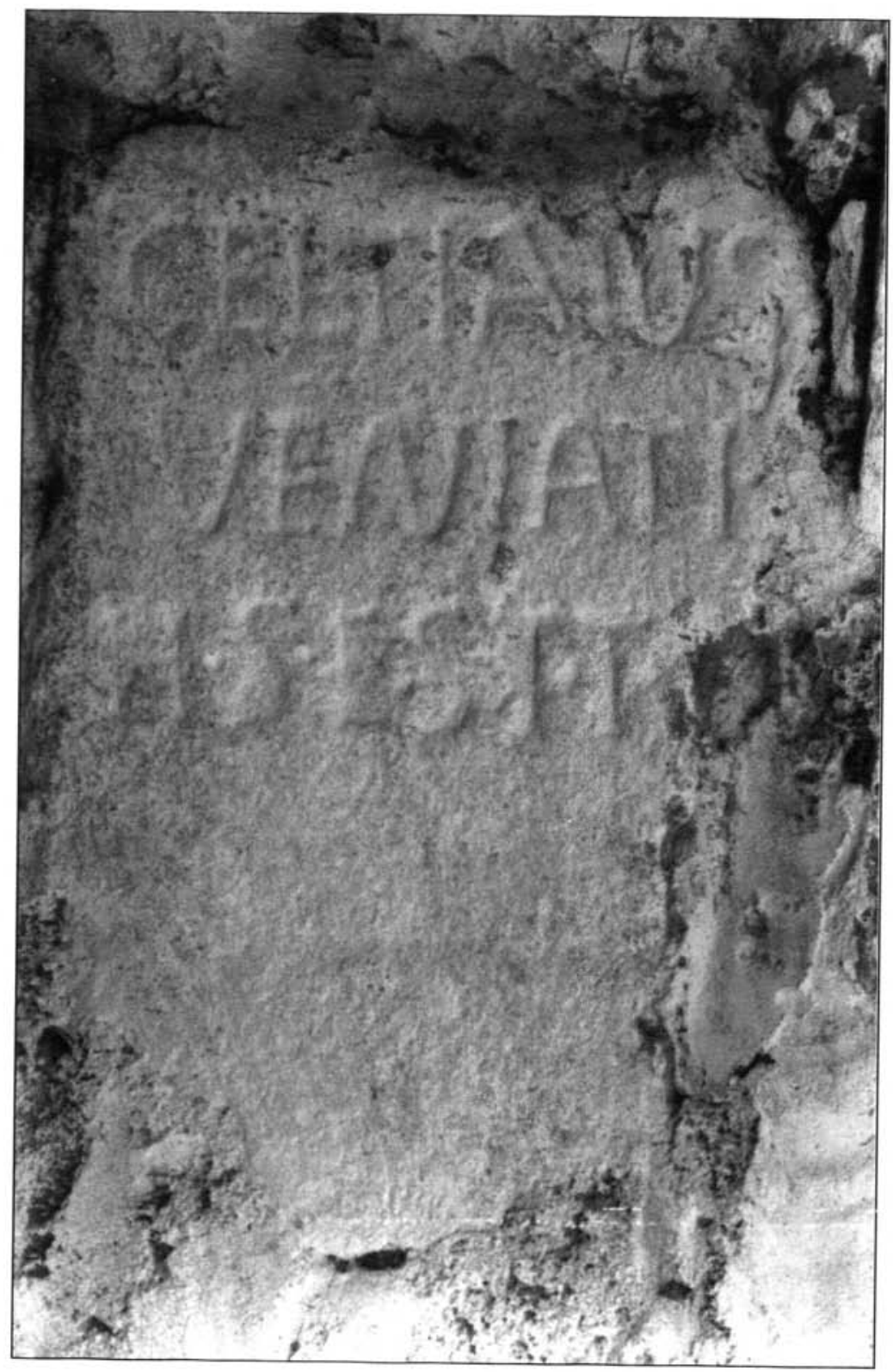

Figura 8: Alcollarin 


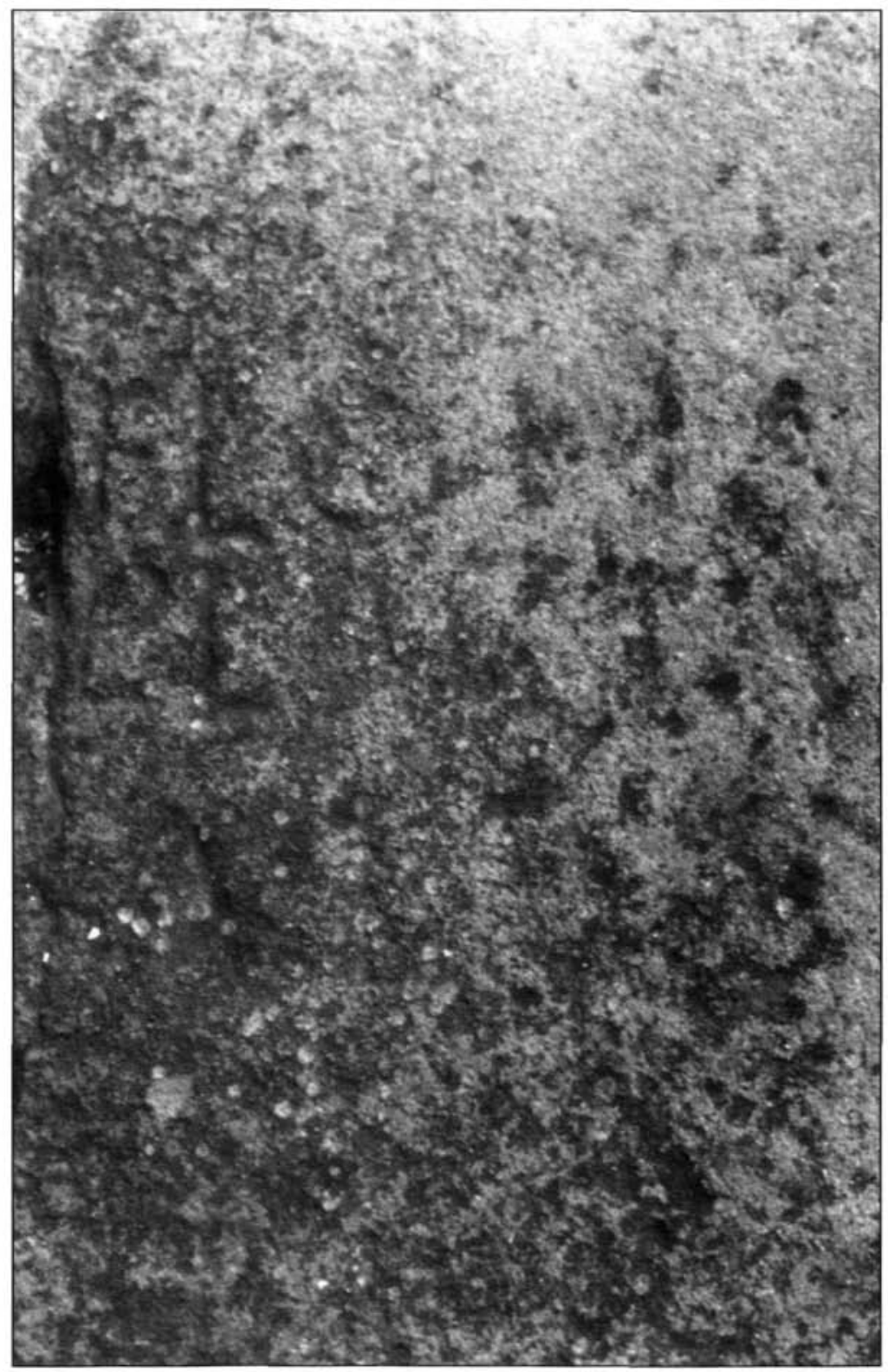

Figura 9: Conquista de la Sierra 


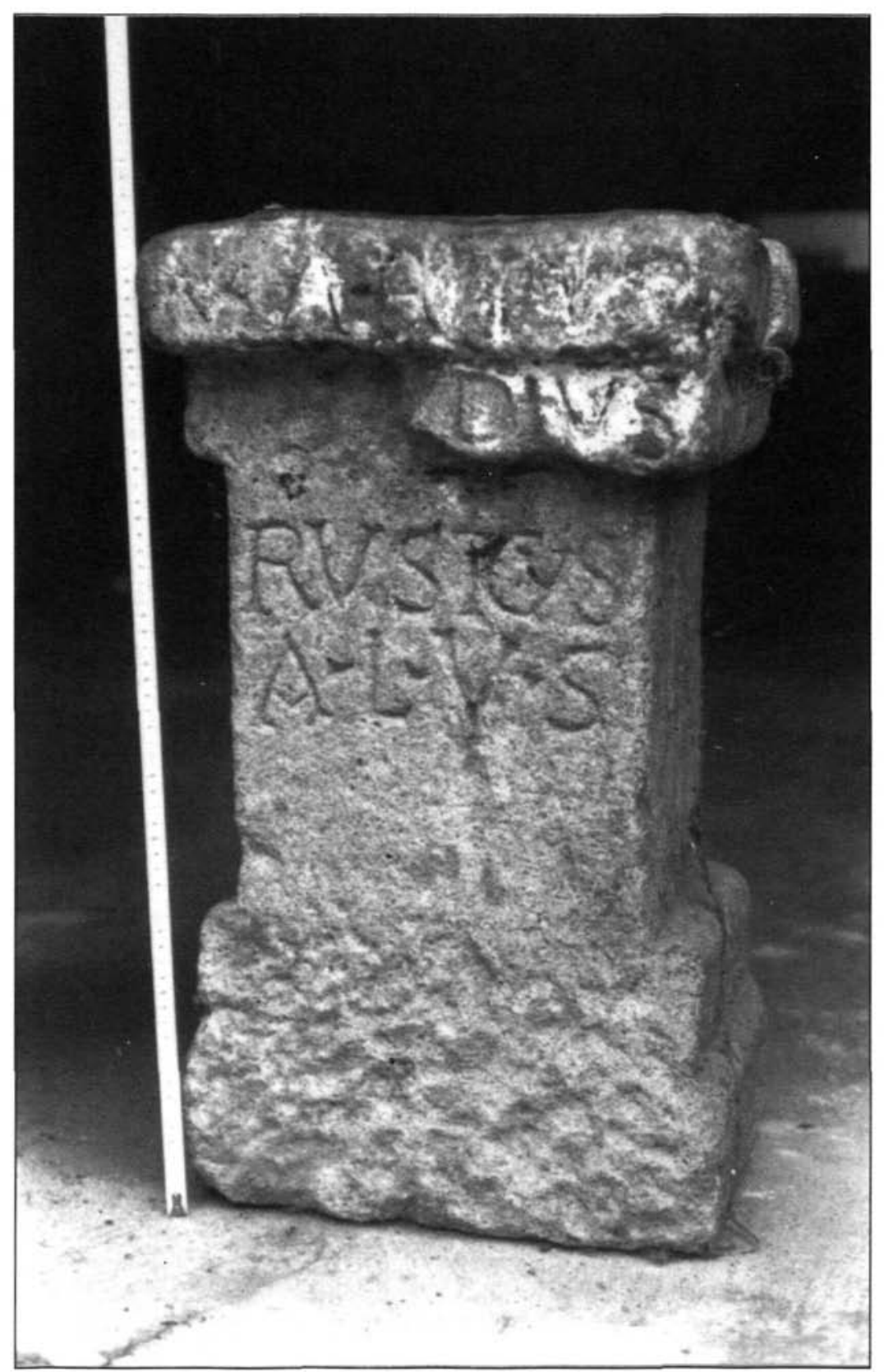

Figura 10: Garciaz 


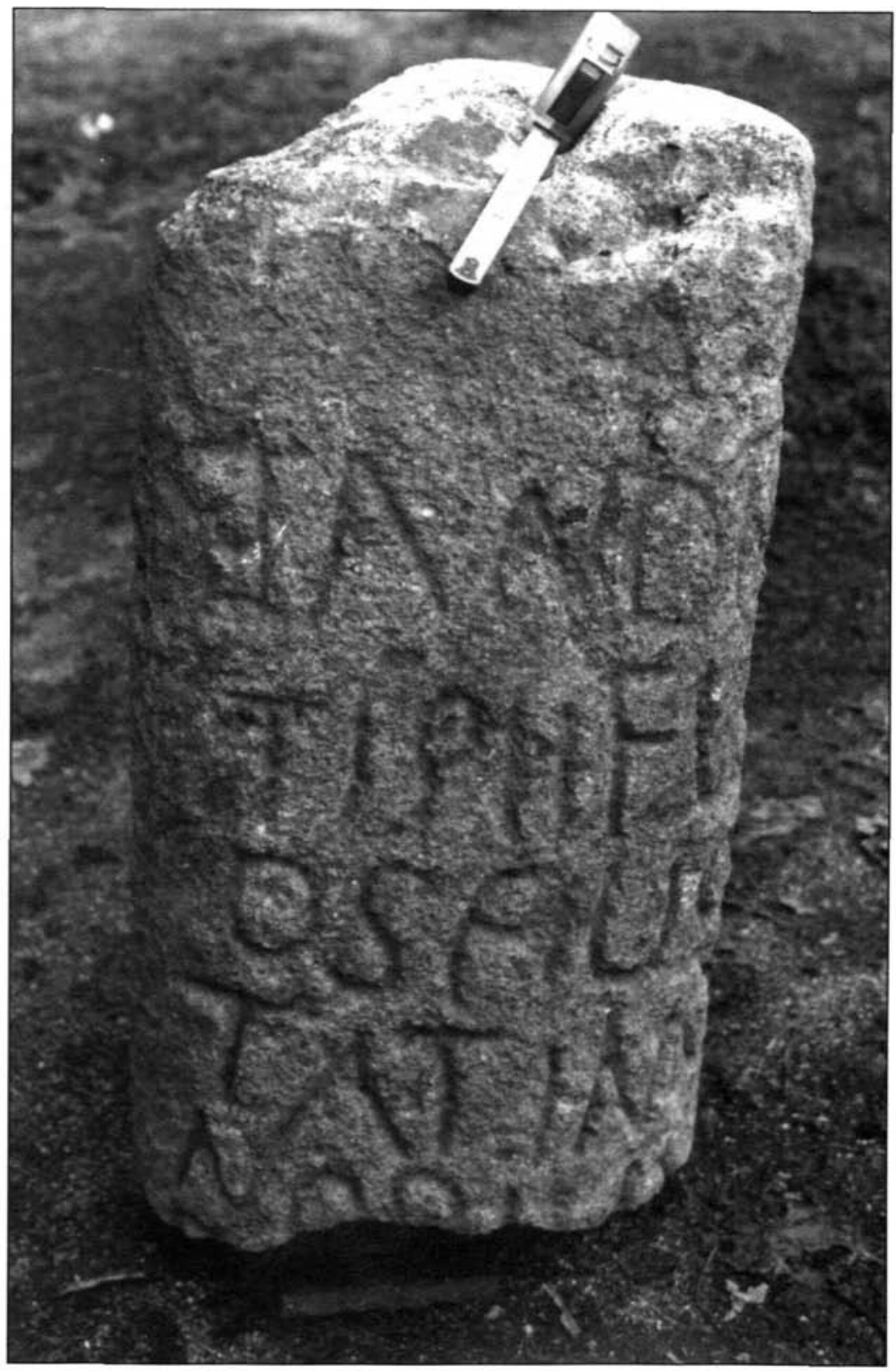

Figura 11: Jarandilla de la Vera 


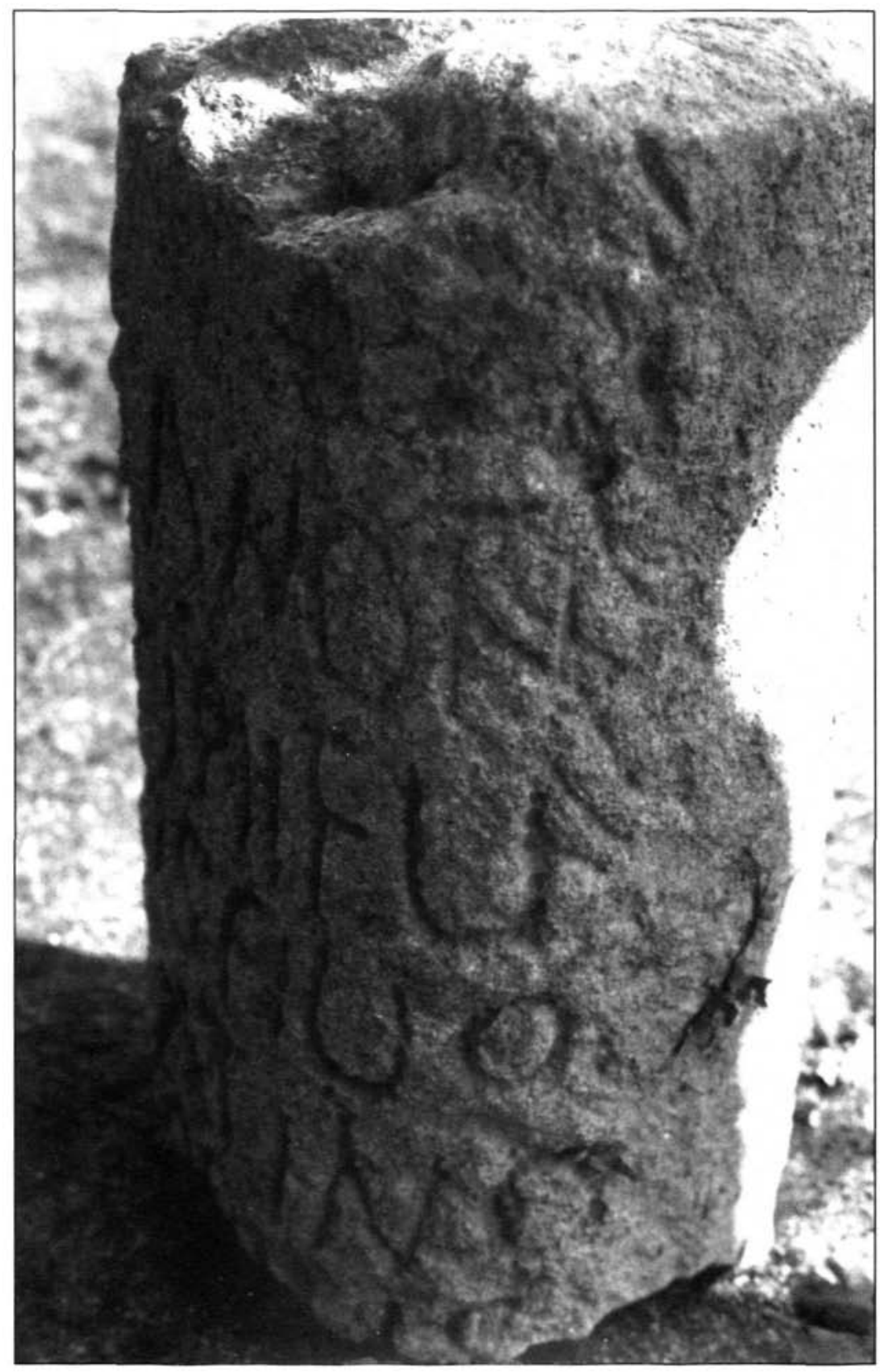

Figura 12: Jarandilla de la Vera 


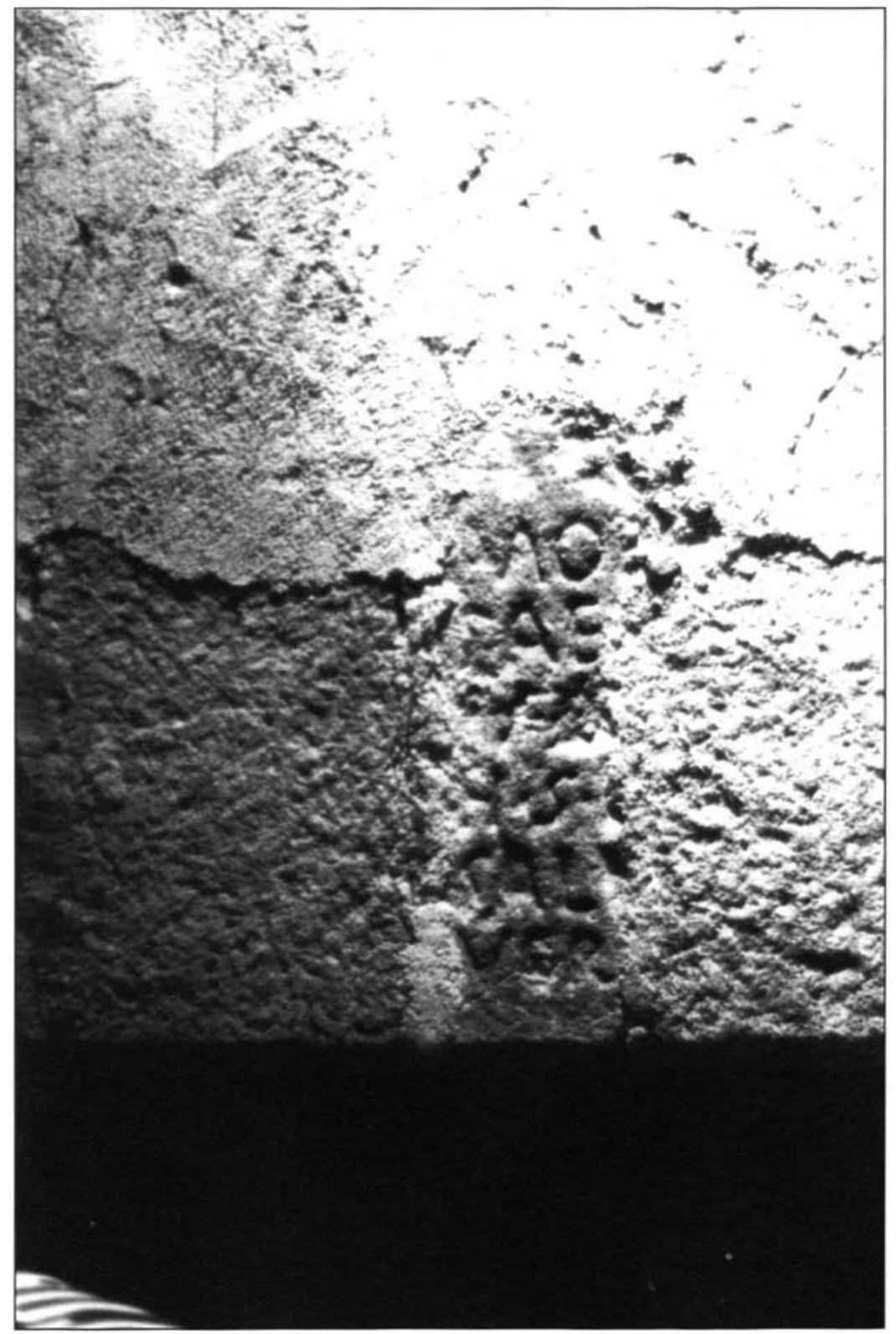

Figura 13: Puerto de Santa Cruz 


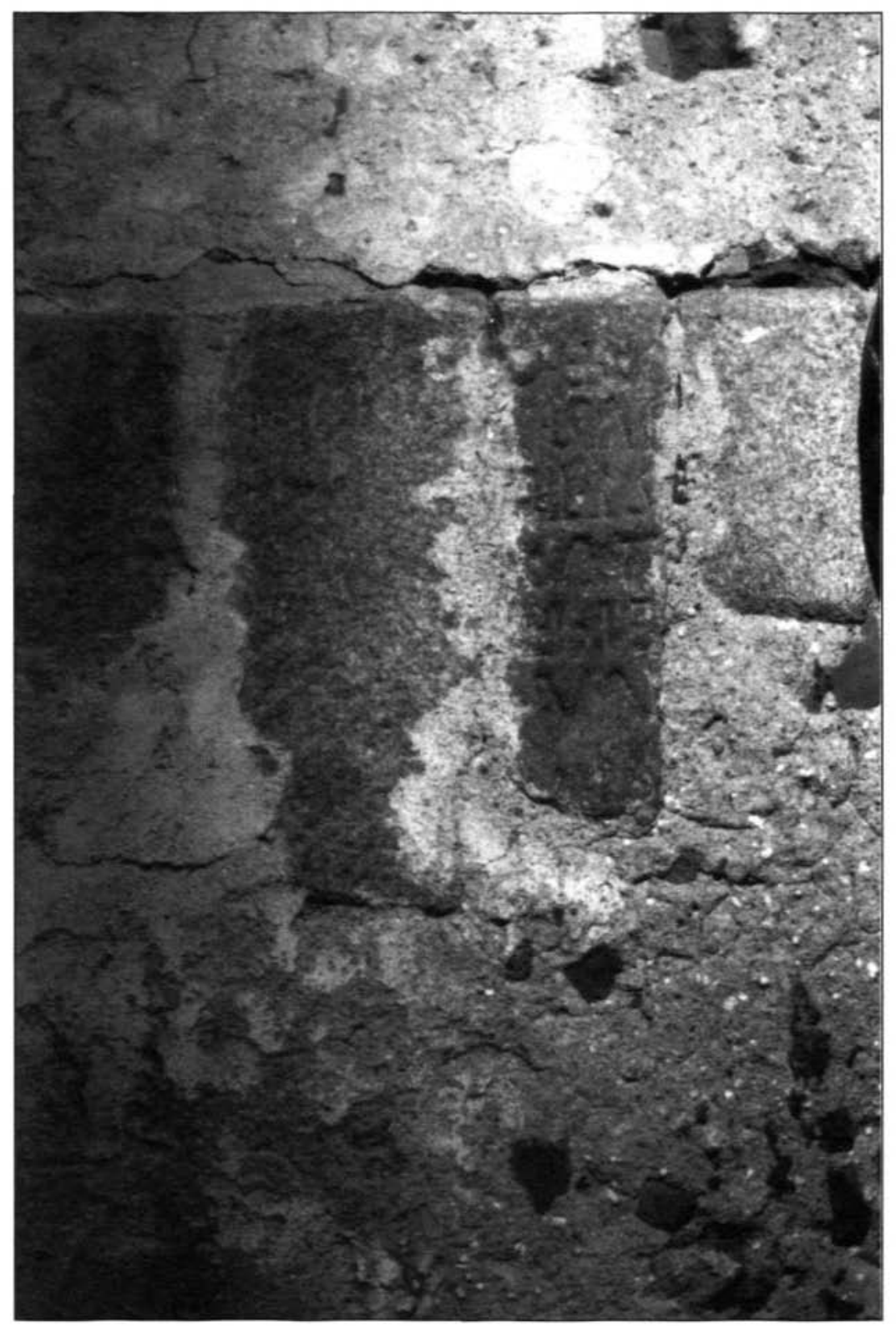

Figura 14: Puerto de Santa Cruz 


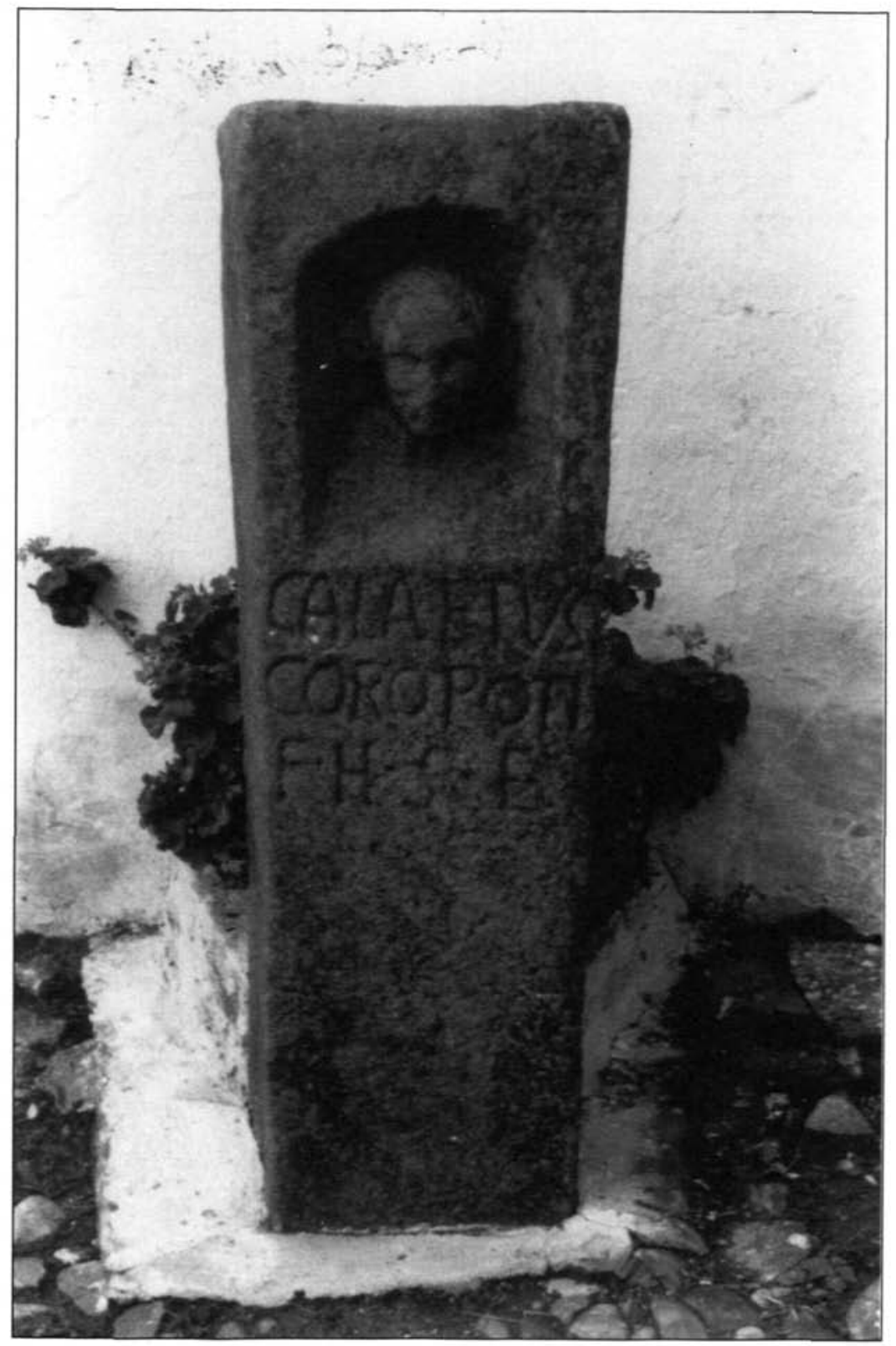

Figura 15: Torrejón El Rubio 


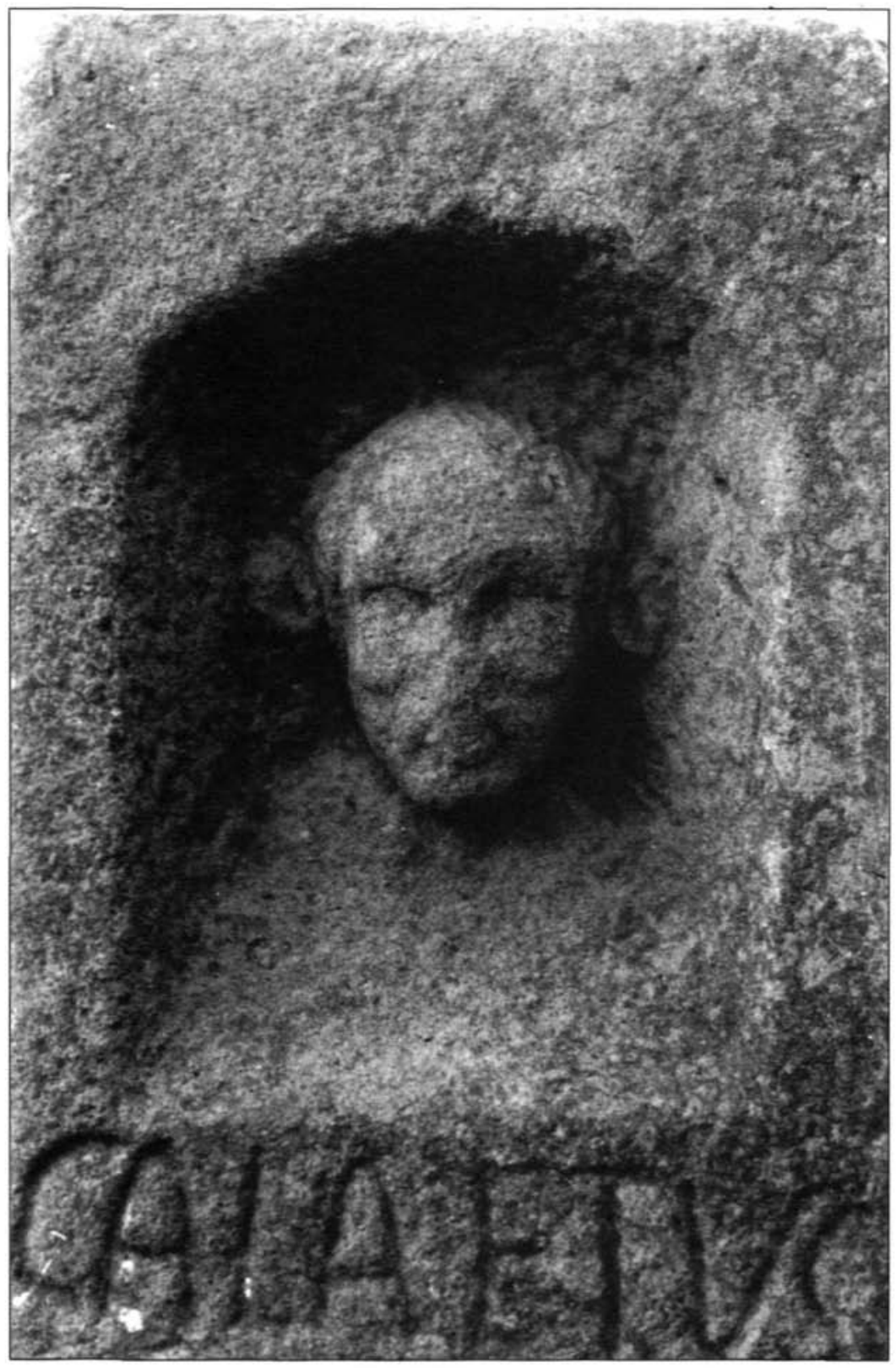

Figura 16: Torrejón El Rubio 


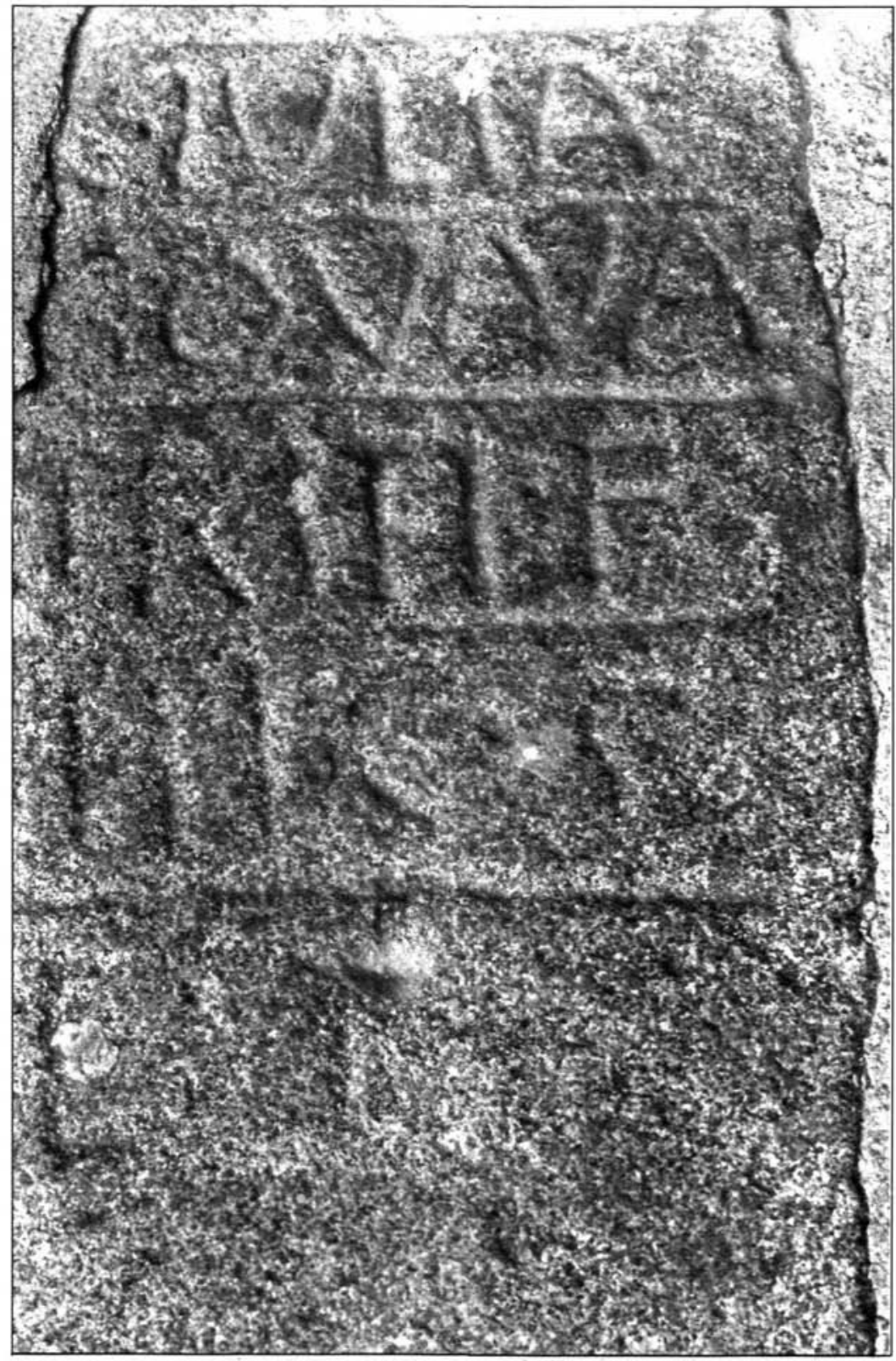

Figura 17: Villamesías 


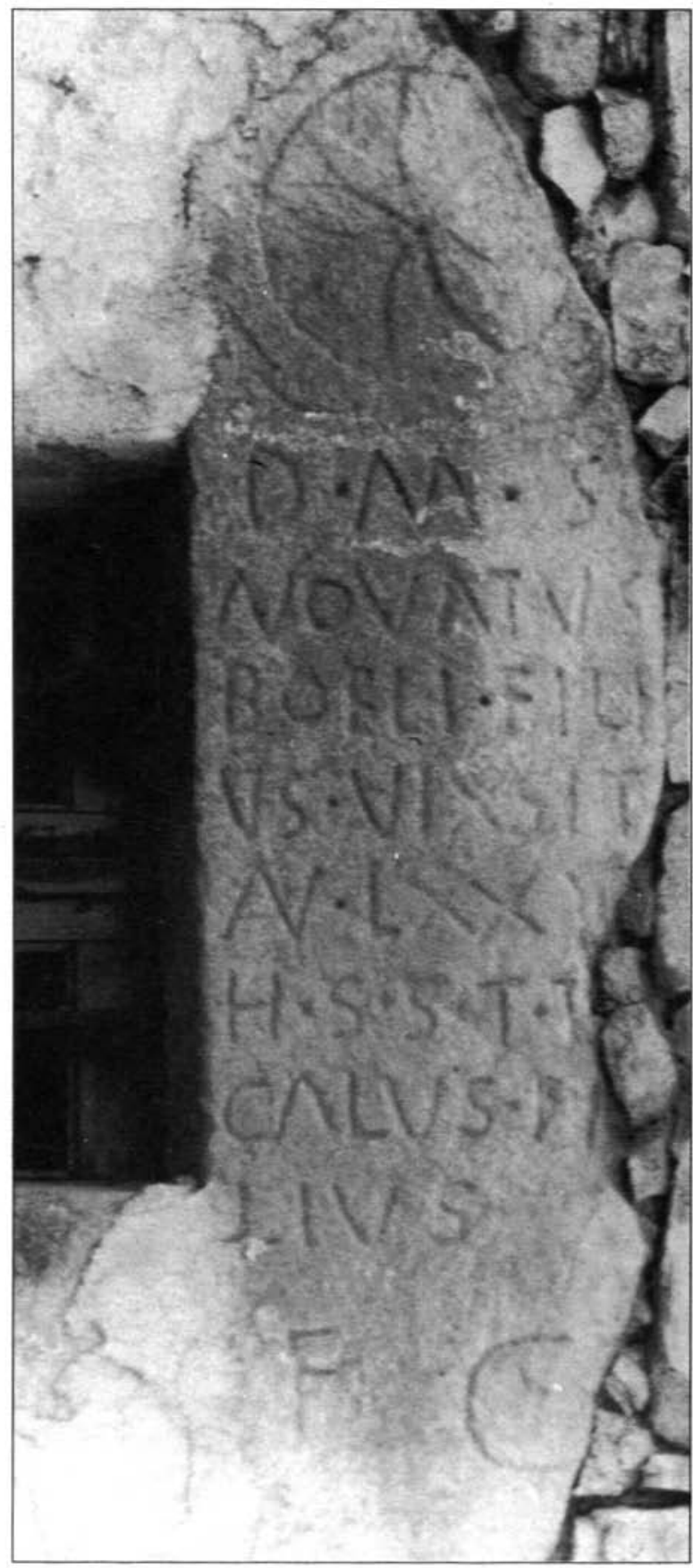

Figura 18: Villamesías 


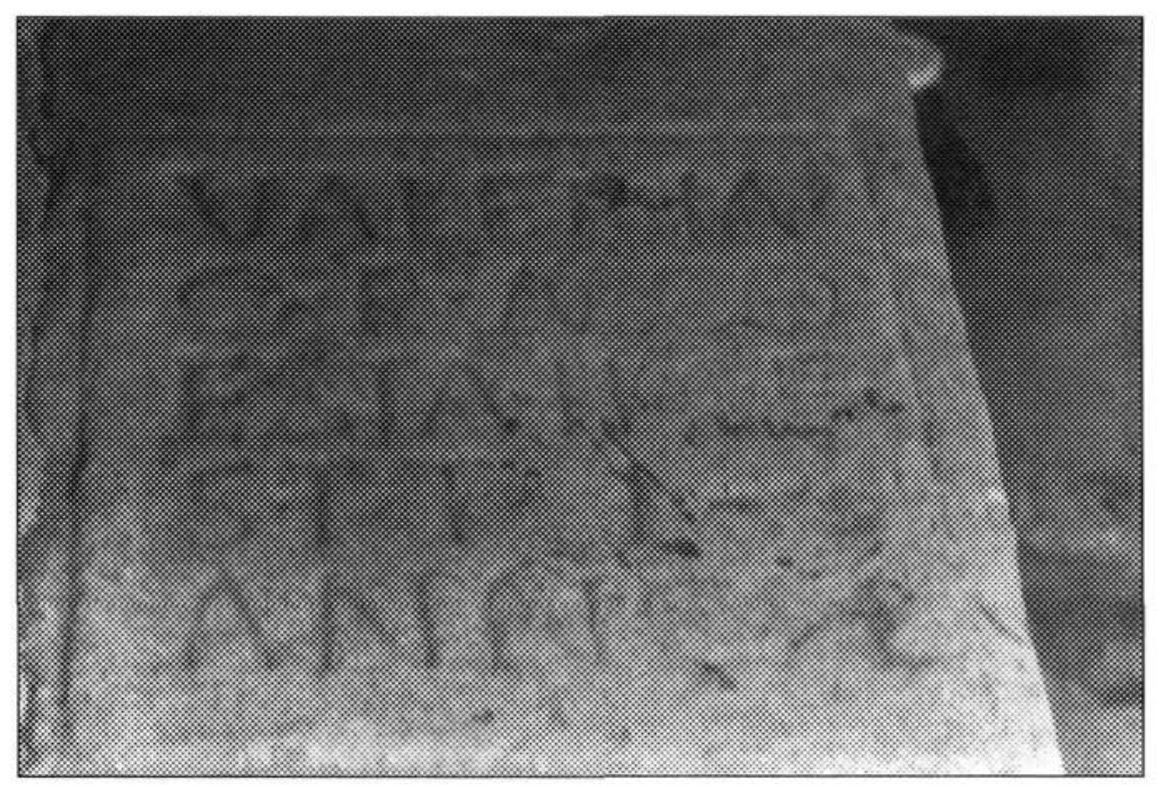

Figura 19: Villamesías

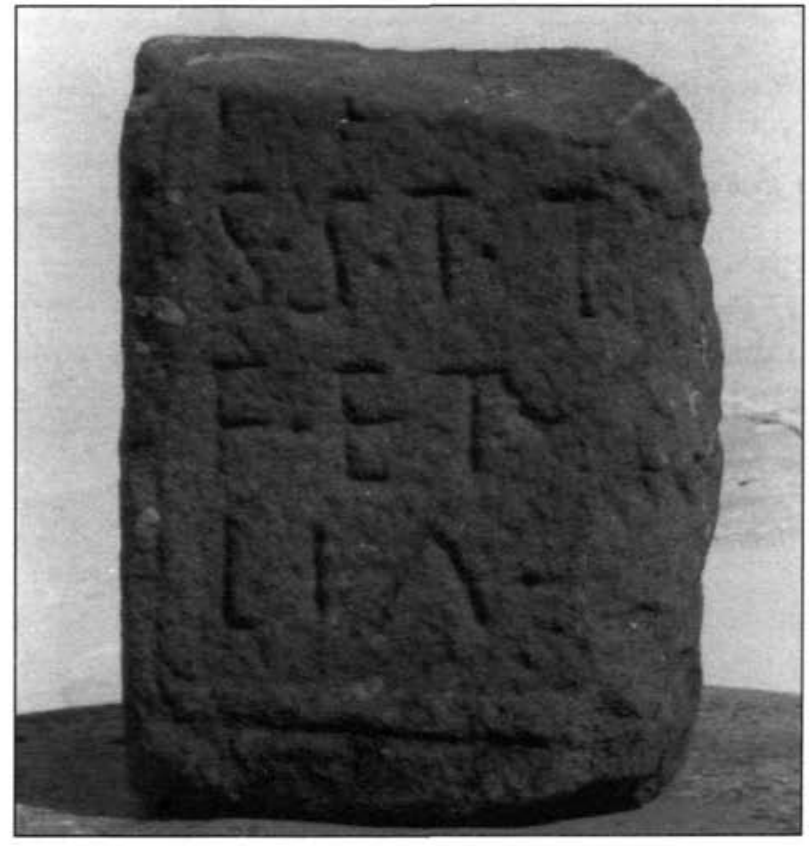

Figura 21: Villamesías 


\section{ONOMASTICA}

\section{I.1 NOMINA}

[-] [Cla?] udius Rusticus, 9

Q. Faracius Verus, 2

Flonia Pla[- - -], 8

C. Iulia Bovâna Tritif., 13

L. Pomon [i] us Mode[s]tus, 4

Valeria Q. f. Modesta, 15

[.] oscia [- ], 5

\section{I.2 COGNOMINA Y NOMBRES INDIVIDUALES}

Afelia, 6

[A.?]mo[e]na + ae[.]f., 11

Arco, 3

Boeli (gen.), 14

Bovana Tritif C. Iulia, 13

Calaetus Coropotif 12

Calus, 14

Celtiatus Veniati, 7

Coropoti (gen.), 12

Elandêt(us) Tir ii f(i)li us, 10

Elea Tancini $f 1$

Lancius Arconis $f$., 3

Modesta, Valeria Q.f., 15

Mode[s]tus, L. Pomon[i]us, 4

Novatus Boeli filius, 14

Pla[- - ], Flonia, 8

Pomponi[a], 3

Rusticus, [-] [Cla.?]udius, 9

Sall.Jius, 11

Tancinus, 1

Tatianus, 10

Tir ii (gen.), 10

Veniati (gen.), 7

Verus, Q. Faracius, 2 


\section{DIVINIDADES}

Mars, 9

\section{LUGARES DE PROCEDENCIA}

Abertura, 1-6

Alcollarín, 7

Conquista de la Sierra, 8

Garciaz, 9

Jarandilla de la Vera, 10

Puerto de Santa Cruz, 11

Torrejón el Rubio,12

Villamesías, 13-16 


\section{BIBLIOGRAFIA}

AlberTos M. L., 1966: La onomástica personal primitiva de Hispania Tarraconense y Bética, Salamanca.

CPILC, R. HURTADO DE SAN ANTONIO,1977: Corpus provincial de inscripciones latinas (Cáceres), Cáceres. DomingueZ DE LA ConCHA.,A. 1990: Antroponimia del suroeste de la Península Ibérica. Memoria de licenciatura inédita, Universidad Complutense, Madrid, 1990.

Fernandez OxeA L. R., 1951: "De epigrafía cacereña^, Boletín de la Real Academia de la Historia 128, 1951.

HAE.: Hispania Antiqua Epigraphica

HEp 1, 1989: Hispania Epigraphica.

ILER.: J. VIVES, 1971: Inscripciones latinas de la España romana, Barcelona, .

KRAHE, H., 1929: Lexikon altillyrischer Personennamen, Heidelberg.

Melida, 1924: Catálogo Monumental de España. Provincia de Cáceres. (1914-1916). Madrid.

PALOMAR M. L., 1957: La onomástica personal prelatina de la antigua Lusitania, Salamanca.

Roso DE LUNA M., 1904: "Nuevas inscripciones romanas de la región norbense", Boletín de la Real Academia de la Historia 44, pp. 113-137.

... 1905: "Nuevas inscripciones romanas de la región norbense". Boletín de la Real Academia de la Historia 47,1905 , pp. $60-71$.

SounN H., 1982: Die griechischen Personennamen in Rom. Berlin / Nueva York.

SORIA SANCHEZ V., 1980: "Historia y Prehistoria de Extremadura”, X Coloquios Históricos de Extremadura, Trujillo, 25-28 de septiembre de 1980. Trujillo, pp. 28-29.

... 1983: "Armas en la Edad del Bronce en Extremadura", Gladius 16,1983, pp. 201-208.

... 1985: "Descubrimientos arqueológicos en Extremadura", XVII Congreso Nacional deArqueologia (Logroño, 1983), Zaragoza, 1985, pp. 483-499. 